\title{
Culture Studies: A Bridge from Native Cultural Content to Learners' Intercultural Competence
}

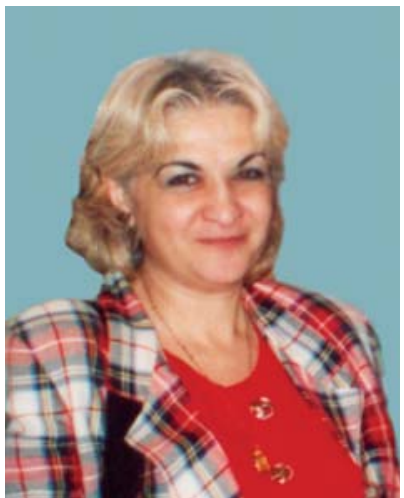

Gayane Gasparyan

Concentration on the communicative methods of foreign language teaching in recent decades has brought about a remarkable shift of focus towards sociocultural content and, in a further development, towards the intercultural approach. As a result, new concepts have been introduced into foreign language didactics and methodology, where the communicative approach and its intercultural background now predominate.

In the 19th and 20th centuries the prevailing method of foreign language teaching was the grammar-translation method, concentrating on the presentation and analysis of the correct linguistic form, accurate translation and the reading of literature. With respect to socio-cultural context, it was merely concerned with the selection and presentation of socio-cultural achievements, such as arts and literature, personified by great people and events in the history of the target country. In its more modern version, it also comprised "facts and figures" (realia) and "life and institutions" of the target country.

The communicative approach developed from the late 1970s, concentrating on speech acts characteristic of everyday communication and emphasising the use of authentic texts.

Since the 1980s, the intercultural approach has developed, concentrating on language awareness, the discussion of cross-cultural experiences, the consideration of stereotypes, the negotiation of meaning, etc. This has led to a perspective of teaching that concentrates on socio-cultural content, i.e. the presentation of information according to a preconceived view of the world of the target language.

On the one hand, documents like syllabuses and textbooks present a variety of methods and approaches to foreign language teaching. On the other, however, as is mentioned in Gerhard Neuner's article on socio-cultural interim worlds in foreign language teaching and learning, the perception of the foreign world by the learners and its representation in the learners' imagination, which may vary considerably, also plays a part. Students quite often do not learn what they are supposed to learn, they do not simply adopt the pre-formed and "prescribed" view of the target world presented in their 
textbooks, but in their minds they create (or have already created) their own images and fantasies about the foreign world which are unstable and may in the process of learning the target language undergo remarkable changes ${ }^{1}$.

Thus, the traditional grammar-translation method with its linguistic limitations has developed into a broader methodology of foreign language teaching based on the "language within culture"/“culture within language" model, where the social environment of the target language with its cultural background, norms and values predominates. The creation of the "new world" in the learner's mind makes the latter feel more comfortable in different, mutually complementary cultural contexts and allows him/her to share and deal with new cultural values.

Hence, what a foreign language teacher is supposed to do is to create a correct and stable "foreign world" in the learner's mind and to make learning of the target language a process of acquiring its cultural content and socio-cultural background.

Moreover, the learner's cultural awareness should be supplemented by special courses, providing extralinguistic, general information concerning the country and its native realia. One such course is known as Cultural Studies.

In different countries this subject has come to have different names for what it provides. It is Area Studies in the United States, Civilization in France, Ñ ò à í î â åä å í è å in Russia, ŁnunuqhunnıpjnıG in Armenia, and Cultural Studies in Britain. The most appropriate term for the development of cultural awareness is Cultural Studies, since it covers all those spheres of native realia which are necessary to create the socio-cultural content of the language being studied. An academic course in Cultural Studies helps university students to perceive deeper meaning within the foreign language media in the extralinguistic context of the "new world", emphasising competences related to the intercultural dimension.

For a very long time the course in Cultural Studies delivered in our country for students of Foreign Languages has been a lecture course. It has covered different aspects - history, geography, social life, economic and political activities, customs, traditions and everyday life - thus giving broad information about different spheres of nativespeakers' lives.

But while this course is theoretical, it must also have a practical goal. The process of teaching foreign languages is not a process of making students familiar with new ways of expressing a different language code. It should be a natural process of involvement in a different national culture, new ways of thinking and national psychology.

The course in Cultural Studies should therefore support the process of teaching language as a code. The process of teaching a foreign language must be exactly based on the national cultural psychology of the native speakers of the language. The language means (pronunciation, grammar, vocabulary and structures) must be exposed from the point of view of their cultural and psychological background.

Thus, the use of extralinguistic and cultural potential within the process of teaching a foreign language, which has been gaining momentum in the past twenty years, has become one of the chief goals of communicative linguistics. It deals with one of the main aspects of general linguistics - the correlation of language and speech, and language and 
thought. It will help to develop new methods and ways of teaching English as a foreign language, based on the psychological factors of a language mechanism.

The course in Cultural Studies must become the so-called bridge between nativespeakers' cultural context and learners' cultural awareness, providing the necessary information for creating the "new world" in the learner's mind. The learner in this case will be prepared to embrace the cultural context of the language which he/she is studying, to perceive the full value of language realia, and to acquire competence for intercultural communication.

\section{References:}

1. Byram M. (Ed.) “Intercultural Competence”. Council of Europe, July 2003, p.18.

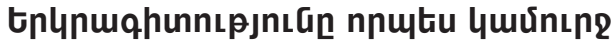

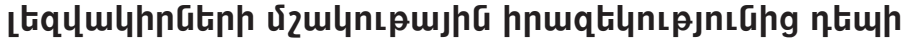

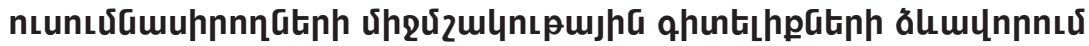

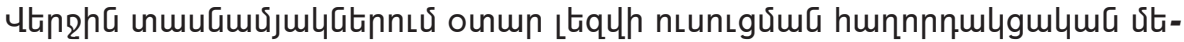

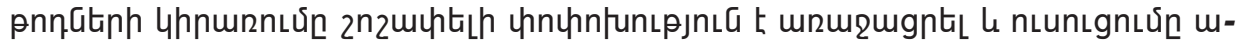

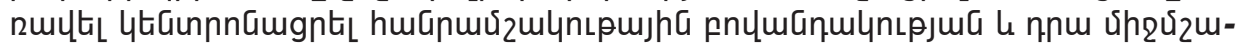

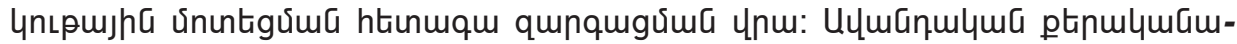

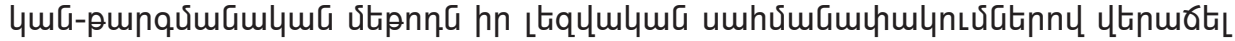

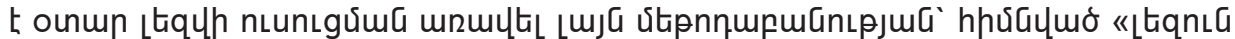

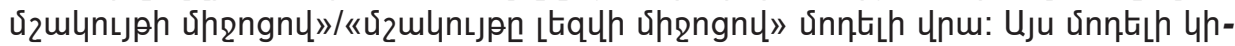

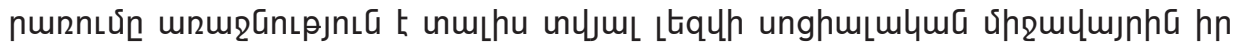

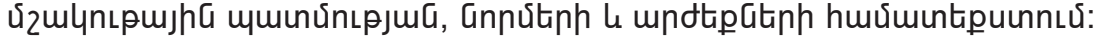

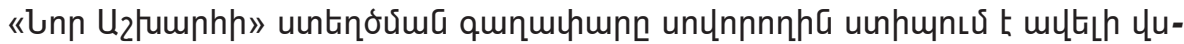

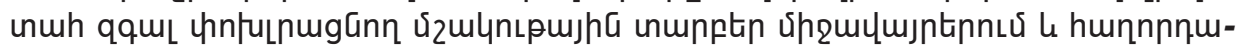

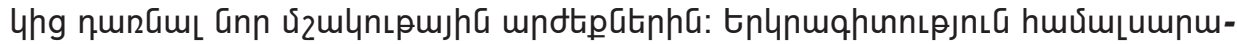

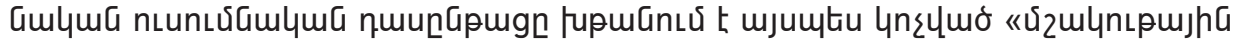

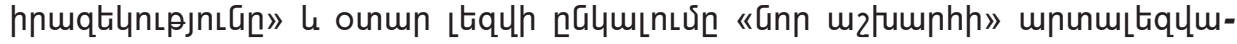

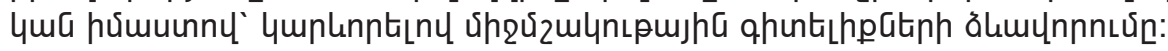

